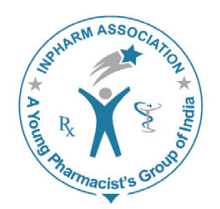

\title{
The Nine-Star Pharmacist: An Overview
}

\author{
Aaseer Thamby Sam ${ }^{* 1}$ and Subramani Parasuraman ${ }^{2}$ \\ ${ }^{1}$ Unit of Pharmacology, Faculty of Pharmacy, AIMST University, Bedong 08100, Kedah, Malaysia. \\ ${ }^{2}$ Unit of Pharmacy Practice, Faculty of Pharmacy, AIMST University, Bedong 08100, Kedah, Malaysia.
}

The pharmacy profession has evolved considerably since its inception centuries ago. The ever-changing scenario in the pharmacy world has resulted in certain that pharmacists must fulfill, in order to provide top notch pharmaceutical care services to each patient. These criteria are more pertinent to pharmacists in the hospital and clinical settings. The WHO introduced the concept 'Seven-star pharmacist', detailing the roles each pharmacist must perform: care-giver, decisionmaker, communicator, manager, life-long-learner, teacher and leader. ${ }^{1}$

The 'seven-star pharmacist' was a landmark concept in terms of setting benchmarks for pharmacists to provide very high quality pharmaceutical care to the patients. An addendum to the seven-star pharmacist concept has resulted in the inclusion of two new criteria, thereby giving rise to the 'Nine-star pharmacist'. In addition to the seven roles, the inclusion of pharmacist as a researcher and an entrepreneur is quite significant.

\section{Pharmacist as a Researcher}

Research is not just for academicians. A great deal of research takes place at grass roots level. Research findings

\begin{tabular}{|c|c|}
\hline \multicolumn{2}{|c|}{ Access this article online } \\
\hline Journal Sponsor & \multirow[b]{2}{*}{$\begin{array}{l}\text { Website: } \\
\text { www.jyoungpharm.org }\end{array}$} \\
\hline \multirow{2}{*}{ www.phcog net } & \\
\hline & $\begin{array}{l}\text { DOI: } \\
\text { 10.5530/jyp.2015.4.1 }\end{array}$ \\
\hline
\end{tabular}

*Address for correspondence:

Mr. Aaseer Thamby Sam, Unit of Pharmacology, Faculty of Pharmacy, AIMST University, Bedong 08100, Kedah, Malaysia.

E-mail:sam_thamby@aimst.edu.my can impact on all sectors of the pharmacy profession. A culture change is needed whereby pharmacists see research as a core part of their normal daily practice. There is a need for more practice research to help the profession meet its aspirations Pharmacists need help and advice about how to get involved. ${ }^{2}$

A Pharmacist can focus into the domain of research pertaining to development of medications, rational drug therapy, and discovery of novel preparations. Pharmacists have vital roles in all aspects of biomedical research, from pre-clinical studies to clinical research.

The Canadian Pharmacists Association (CPhA) defines pharmacy practice research as a component of health services research that focuses on the assessment and evaluation of pharmacy practice. While this definition is clearly unique to the profession, not all research in which pharmacists are involved reflects their practice, nor can it solely reflect the practice of pharmacists, especially in the era of collaborative practice teams. Additionally, research done by pharmacists may address important questions that facilitate improved patient care or service delivery, without specifically advancing pharmacy practice, but still contributing to the scientific literature as a whole. ${ }^{3}$

In 1997, the King's Fund described pharmacy practice research as "research which attempts to inform and understand pharmacy and the way in which it is practised, in order to support the objectives of pharmacy practice and to ensure that pharmacists' knowledge and skills are used to best effect in solving the problems of the health 
service and meeting the health needs of the population". ${ }^{4}$ This umbrella definition affords us a better perspective of pharmacy practice research as an entity that encompasses both large-scale, multi-site projects and small-scale projects undertaken to improve understanding of local or practicespecific issues. Pharmacists strive to improve the quality of their existing services and to develop new ones in order to benefit their patients. Often this is hampered by a lack of easily accessible evidence both locally - within primary care trusts, local health boards and strategic health authorities and nationally in the form of published evidence that informs national guidelines around best practice. Pharmacists in all settings can engage more fully in research in order to improve patient outcomes and further develop the profession. Research is needed in order to inform workforce development, education, practice and commissioning decisions. Community pharmacists can make a significant contribution to pharmacy practice research initiatives. These initiatives can take the form of small scale local projects that identifies patient needs or evaluate the effectiveness of new services. This not only benefits the health of the local population but, if shared appropriately, the data and findings generated could be used to inform a larger study, ultimately influencing wider service development and the development of pharmacy. ${ }^{2}$

The American College of Clinical Pharmacy (ACCP) has defined clinical pharmacy as "that area of pharmacy concerned with the science and practice of rational medication use". This definition offers a more contemporary perspective of pharmacy. Clinical research according to the ACCP is "studies of human subjects, including surveys, cross-sectional studies, case-series, case-control studies, cohort studies, first-in-human studies, proof-of-principle projects and all phases of clinical trials". 5

Pharmacy research should not be confined within the community settings. Hospital pharmacists are increasingly engaged with research as an integral part of their career development - keeping up to date with, and contributing to, research and developments, often in collaboration with medical staff and colleagues in the pharmaceutical industry. ${ }^{6}$

Primary care pharmacists represent a key group within the pharmacy field, who could make a large impact due to their involvement in primary health care interventions, pharmaceutical needs assessment, research and development agenda. A general blue print for the importance of research is to conduct and use various research methodologies to identify local needs that incorporate and build on pharmaceutical needs assessments and to develop services and evaluate them in terms of clinical outcomes, patient satisfaction and value for money. ${ }^{2}$

\section{Pharmacists as 'Pharmapreneurs'}

An entrepreneur is 'a person who organizes and operates a business or businesses, taking on greater than normal financial risks in order to do so'. Entrepreneurs are usually viewed as individuals who take substantial risks to go out and start new companies. The concept of 'Pharmapreneur' is still in its infancy because unfortunately, the mindset of almost all fully-registered pharmacists (and pharmacy graduates) is that their profession extends to only drug dispensing and its associated activities within a hospital or clinical setting. Most pharmacists go to work for entities that are already established, such as a community pharmacy or hospital. Such positions are generally considered safe, as they promise a steady paycheck and continued employment. For that reason, entrepreneurship is not commonly listed among a pharmacist's skill sets.

Pharmaceutical businesses have infinite opportunities, more so for pharmacy graduates. The current scenario is that many entrepreneurs with little or no knowledge of pharmacy set up 'pharmacy shops' to procure and dispense medications, under the supervision of a registered pharmacist. The question posed at this juncture is: 'Why cant pharmacists evolve into Pharmapreneurs??

Pharmapreneurs comprise a number of highly qualified and diversified personnel having had sales, marketing, key accounts and market access experience with multinational and local companies. The possible areas for involvement of pharmapreneurs are market access landscape navigation, new products launch, top-line sales protection plans, reimbursement strategy, mature brand life-cycle maximization, risk assessment and mitigation scenario planning, sales force excellence and divestitures. ${ }^{8}$ The Pharmapreneur must...

- possess and apply appropriate pharmaceutical sciences knowledge

- perform pharmacist-directed patient care

- solve problems and continue to learn as the healthcare laws and policies change

- enhance patient care by creating new outcomes improvements paradigms

- innovate new pharmacy business solutions that enhance the patient experience and strengthen the business of community pharmacy. 


\section{Basic pointers for aspiring pharmapreneurs}

Be paranoid

All great leaders must fear that they are one day away from 'losing their edge' or business. This scenario should generate fear that drives them to keep evolving, learning new things and innovating. Updating knowledge, skills, and abilities renders a pharmapreneur sharp and competitive, as well as preparing them for whatever the future has in store.

Remember that all decisions have risk

Many pharmacists hesitate to become a pharmapreneur because making the decision to join a start-up business is risky. All of us are one decision away from not being needed or from getting replaced with someone better or cheaper. Thus, there is risk in staying in a current position, just as there is risk in taking a new one.

\section{Find mentors}

Aspiring pharmapreneurs must maintain a network of individuals with whom they can discuss new opportunities, issues etc. Engaging with those who have different backgrounds and experiences, in addition to those who are doing similar vocations, is important for achieving success. ${ }^{9}$

\section{Steps to evolve into a Pharmapreneur}

Business classes typically study other businesses to attempt to learn from (and prevent repetition of) their mistakes. Several classic errors made by business owners should be on the watch list of any pharmapreneur. The following pointers will be very handy for the budding pharmapreneur.

Make sure you know the pharmacy inside and out before starting a pharmacy business

A surprising number of pharmacists assume that running a pharmacy is not that different from operating other businesses. Although inventory, sales, taxes, employees, clients, and fees are similar, the legalities, licensing, risks, and specific peculiarities of pharmacy known to any experienced pharmacist-owner may not be known to the aspiring pharmapreneur and can persuade potential partners and/or clients that the business is not professional. A very important aspect is to never structure a pharmacy business so that a non-pharmacist decides how the business will work, settles medication prices, or establishes the type of pharmaceutical services to be offered.

Work for another self-starter first before trying your own business

It will cost far less to work first for another successful pharmapreneur before going out and setting up your own pharmacy shop. It is vital to learn from someone else's mistakes, ask for advice, and see whether they have the zeal to deal with all the problems that can occur in a given week.

Dont overinvest in equipment or space when youre getting started The initial investment to commencing the pharma venture should be channeled towards medications and the bare essentials for work equipments and optimal space. As the business flourishes, the attention could turn towards costlier medications and even more equipments. The pharmapreneur can expand the work space, only when the venture has progressed successfully in monetary terms.

Do your homework

The aspiring pharmapreneur should first conduct a market research on the feasibility and viability of opening a pharma business in that particular locality, the effect it has on the residents of that said area/community, the financial investments and returns. The first step is to get a feedback from the residents of that area regarding the same.

Listen to your customers

Successful pharmapreneurs must always listen to their customers, in order to gauge the needs and requirements of them.

Notice other businesses that fail and try to discover how to avoid repeating their mistakes

A pharmapreneur must not only gain knowledge from successful ventures of other pharmapreneurs, but must also analyze why certain pharma businesses are floundering, so as not to make similar errors.

Find your reason for starting a business

The initial step to commencing a pharma business is to truly know and understand the professional and personal reasons for the same.

Do you have the income to get through lean times?

More than half of new businesses usually fail in the first 5 years. What often makes the difference is having enough income to stay afloat until the business turns a profit.

Who will offer services and run your business in your absence? To make a new business succeed requires an enormous amount of physical energy and a good backup plan. It is essential to know someone who can be trusted to lead or govern the pharma business in the absence of the pharmapreneur. It is impossible to overestimate the importance of having a backup plan. 
Is this business a new concept or a modification or new outlet for a recognizable pharmacy product or service?

The pharmapreneur must ask him/ herself: Whom will the business serve? Will this business be viable? Will I require the help of other healthcare professionals, pharmacists, pharmacies, or the public? What do potential customers think of this idea? Has anyone done this before? What were the results of those earlier ventures?

If a pharmapreneur wants to create a wholly new concept in pharmacy and offer it as a service, they may need to create not only the service, but also the market for it. They may have to educate patients about why they need the service, sell it to them, and build their clientele. They must be prepared as this could take a long time. ${ }^{10}$

The crux of the matter is analyzing to what extent educational programs stimulate and enhance pharmacy student's intellectual curiosity and entrepreneurial spirit throughout their undergraduate, graduate professional, and/or graduate education. Even more important, to what extent are institutions considering in their admissions processes and procedures for all programs in their colleges and schools the ability to attract and recruit

\section{REFERENCES}

1. Aaseer TS, Subramani P. Seven-Star Pharmacist concept of WHO. J Young Pharm. 2014; 6(2): 1-3.

2. Pharmacy practice research has an impact on each and every pharmacist. Available in http://www.pharmaceutical-journal.com/ opinion/comment/pharmacy-practice-research-has-an-impacton-each-and-every-pharmacist/11001265.article [Last accessed on 07/09/2015].

3. Pharmacy Practice Research. Available in http://www.pharmacists. ca/index.cfm/education-practice-resources/pharmacy-practiceresearch/ [Last accessed on 07/09/2015].

4. Mays N. A new age for pharmacy practice research: promoting evidence-based practice in pharmacy. London: Royal Pharmaceutical Society; 1997.

5. Ahmed SI, Hasan SS, Hassali MA. Clinical pharmacy and pharmaceutical care: a need to homogenize the concepts. Am J Pharm Educ. 2010 Dec 15; 74(10): 193.

6. Liz Seston. Pharmacy Workforce Census 2008: Main findings. Centre for Pharmacy Workforce Studies, School of Pharmacy and Pharmaceutical Sciences, University of Manchester, July 2009. Available in http://www.rpharms.com/about-pharmacy-pdfs/ census08.pdf [Last accessed on 07/09/2015]. applicants who demonstrate intellectual curiosity and an entrepreneurial spirit in addition to strong academic and interpersonal skills. The rate of new knowledge in the biomedical, pharmaceutical, and clinical sciences and the massive information and technologies available to clinicians and scientists will continue to explode, providing new opportunities for those who are willing to learn, integrate, and dream of the possibilities. It is critical that we have future graduates with this intellectual curiosity and entrepreneurial spirit who are playing important roles in the rapidly advancing and changing areas of health care and wellness. ${ }^{11}$ Universities like the 'University of the Pacific' are among many universities in the United States of America offering the programme Entrepreneurial Pharmacy Practice', aimed at developing efficient Pharmapreneurs. ${ }^{12}$ The course offered is a fresh opportunity for pharmacy students willing to forge into a new career path. As the pharmacy world takes rapid strides forward in many domains, it is critical that opportunities are incorporated to stimulate, enhance, and improve pharmacy students' intellectual curiosity and entrepreneurial spirit for pharmacy to maintain its role as a key member of innovative, creative, and dynamic models and systems of health care and health care delivery.

7. Pharmacists as Pharmapreneurs http://www.pharmacytimes.com/ blogs/focus-on-current-inking/0814 [Last accessed on 07/08/2015].

8. Pharmapreneurs. http://www.pharmapreneurs.co.za/services.html [Last accessed on 07/08/2015].

9. Establishing Opportunities for Entrepreneurship in Pharmacy. Available in http://www.pharmacytimes.com/blogs/focuson-current-thinking/0814/Establishing-Opportunities-forEntrepreneurship-in-Pharmacy [Last accessed on 07/08/2015].

10. Starting a pharmacy service business. Available in http:// drugtopics.modernmedicine.com/drug-topics/news/ modernmedicine/modern-medicine-feature-articles/startingpharmacy-service-business?page $=$ full [Last accessed on 07/08/2015].

11. Brazeau G. Entrepreneurial spirit in pharmacy. Am J Pharm Educ. 2013; 77(5): 88.

12. Entrepreneurial Pharmacy Practice Program. Available in http:// www.pacific.edu/Academics/Schools-and-Colleges/Thomas-JLong-School-of-Pharmacy-and-Health-Sciences/Academics/ Doctor-of-Pharmacy/Certificate-and-Dual-Degree-Programs/ Entrepreneurial-Pharmacy-Practice-Program.html [Last accessed on $07 / 08 / 2015]$. 